\title{
ENDOSCOPIC TREATMENT OF CONTAINMENT RING COMPLICATIONS AFTER BARIATRIC SURGERY WITH THE USE OF STENTS: SYSTEMATIC REVIEW AND META-ANALYSIS
}

Dr. Idiberto Jose Zotarelli Filho, MSc, Ph.D ${ }^{1}$

${ }^{1}$ Affiliation not available

May 22, 2020

\begin{abstract}
INTRODUCTION: Obesity is an important health condition that is related to high rates of morbidity and mortality. Bariatric surgery, although effective, has limited indications and may pose a risk of early and late postoperative complications, one of which is related to the gastric retaining ring, such as erosion, sliding of the device, and food intolerance. One of the modalities used in the endoscopic treatment of ring extraction is the use of stents, which represents a minimally invasive, safe, and effective alternative to the detriment of surgical treatment. OBJECTIVE: To characterize the modalities of endoscopic treatment using Stents for the treatment of complications associated with the retaining ring in the postoperative period of bariatric surgery and to determine the success rate of the different methods of endoscopic treatment. METHODS: The present study will follow an international model of systematic review and meta-analysis, following the rules of PRISMA. The search strategies for this systematic review will be based on the keywords (MeSH Terms) "Obesity. Endoscopy. Bariatric surgery. Gastric Bypass. Stents ", with publications between 2010 and 2020, in order to analyze more recent scientific publications. Meta-analysis: A common descriptive statistical analysis will be carried out, obtaining the values of total N, mean, standard deviation, confidence interval (CI), and percentage (frequency) for all predictors. The One-Way test (ANOVA) will be applied, adopting the $\alpha$ level less than 0.05 with a statistically significant difference for the $95 \%$ CI. The value of R-sq (I2) will be analyzed to discover the inaccuracy or heterogeneity of the analyzes. The S factor will indicate the standard deviation between the data points and the adjusted values.
\end{abstract}

Keywords: Obesity. Endoscopy. Bariatric surgery. Gastric Bypass. Stent.

ABC MEDICINE FACULTY

SÂMARA FERNANDES SANTOS MARTINS

ENDOSCOPIC TREATMENT OF CONTAINMENT RING COMPLICATIONS AFTER BARIATRIC SURGERY WITH THE USE OF STENTS: SYSTEMATIC REVIEW AND METAANALYSIS 
Master's Thesis Project prepared at the ABC Health University Center, next to the Post-Graduate Program in Health Sciences (recommended by the CAPES Technical-Scientific Council - Opinion 656/2017).

Concentration Area: Clinical Research

Filho

Advisor: Prof. Dr. Jaques Waisberg

Co-supervisor: Prof. Dr. Idiberto José Zotarelli

2020.

SANTO ANDRÉ - SÃO PAULO- BRAZIL,

\section{INTRODUCTION}

Data from the Ministry of Health show the increasing importance of obesity in the health of the population. The change in habits has made Brazil a country with fewer cases of malnutrition to the detriment of the progressive increase in cases of obesity, with the age group most affected between 45-64 years and similar distribution between men and women ${ }^{1}$.

Public policies are gradually trying to encourage healthy habits that impact the population's diet and lifestyle, as well as investment in drug therapies to control obesity-related comorbidities ${ }^{1}$. However, conservative therapies have high rates of abandonment and are ineffective.

Bariatric surgery, although effective, has limited indications ${ }^{2}$, in addition to offering a risk of early and late postoperative complications ${ }^{3}$. According to the Brazilian Society of Bariatric and Metabolic Surgery, from 2012 to 2017, the number of bariatric surgeries in the country increased by $46.7 \%$. In the midst of this scenario, this type of surgery has aroused surgeons' interest in improving and modernizing their techniques, as well as in addressing their complications, aiming at a safer and more effective treatment ${ }^{4}$.

The most used operative techniques are gastric bypass (Roux-en-Y gastric bypass) and vertical gastrectomy (Sleeve). Gastric bypass is a mixed technique, in which the disabsorptive component is provided by the extension of the intestinal bypass. Several modifications of this technique were created in an attempt to improve weight loss and reduce the number of complications ${ }^{5}$.

Fobi and Capella proposed the placement of a silicone ring in the gastric reservoir, just above the gastrojejunal anastomosis, in order to calibrate its diameter and prevent a possible dilation that would cause weight recovery in the future. Despite the benefit, patients who underwent gastric bypass surgery with a ring may experience late complications of the technique such as food intolerance, erosion, or ring migration ${ }^{5}$. The classic treatment for complications is the surgical removal of the ring, but this approach offers great morbidity and mortality due to possible complications. However, several techniques have been developed, in order to solve the cases in a less invasive way, through endoscopic procedures, without the need for surgical reintervention ${ }^{6}$.

Among the endoscopic techniques, there is the endoscopic removal of the ring through the use of accessories (scissors), pneumatic balloon dilation, and the application of gastric stents (plastic or metallic) with peculiar and specific indications for each type of complication.

Erosion of the retaining ring is a rare complication ${ }^{7,8}$ with an incidence of $1 \%$ to $7 \%$ of patients in the postoperative period. The clinical picture can be asymptomatic as an endoscopic finding or vary from mild symptoms such as epigastric pain, nausea/vomiting, obstructive symptoms and changes in weight (recovery or excessive loss), to more serious complications such as bleeding, intra-abdominal abscess, and fistula formation ${ }^{9}$. 
When less than $50 \%$ of the ring is visible through gastric light, one can use the prosthesis (metallic or plastic) for a period of one to two weeks to accelerate the erosion process, which is based on the necrosis provided by the ischemia in the gastric wall between the prosthesis and the retaining ring $^{8}$.

Ring intolerance may be secondary to gastric stenosis promoted by the ring in its usual position or due to distal sliding. Stenosis can cause constrictive symptoms; the contrasted examination may show a narrowing in the region of the device and, on endoscopic examination, an insurmountable ring constriction or laborious passage of the endoscopy device is noted ${ }^{8}$.

The slip corresponds to the displacement of the prosthesis externally to the gastric pouch in a distal direction that promotes the riding on the jejunal loop, generating extrinsic compression and the consequent difficulty in emptying the gastric pouch with an incidence of less than $1 \%^{9}$. Such slippage can be total or partial, generating a picture with lesser or greater feeding difficulties and vomiting, respectively. The diagnosis of slippage can be performed by means of contrasted radiography observing a poor positioning of the ring in early cases, or even in the identification of late findings such as the increased diameter of the gastric pouch, hydro-aerial level, and wide anastomosis. At the endoscopic examination, dilation of the gastric pouch, gastric residue, esophagitis due to vomiting, the convergence of jejunal folds, and even mucosal prolapse to the gastric chamber.

The treatment for this condition can be carried out with the rupture of the ring by the use of a pneumatic balloon dilator or the extraction of it by the use of stents (plastic or metallic). ${ }^{9}$ The dilation mechanism aims at the rupture of the wire inside the ring by inflating the balloon used for the treatment of achalasia, which has sufficient radial force to rupture the device. Through endoscopic examination, the guidewire is passed through the efferent loop, and, with the aid of fluoroscopy, the pneumatic dilator balloon $(30 \mathrm{~mm})$ is positioned so that it is enclosed by the ring when it is inflated and its rupture in the ring must be accompanied by radioscopy. ${ }^{10}$

The dilation of the esophagogastric transition (TEG) and gastrojejunal anastomosis should be avoided in case of distal migration of the device since jejunum loops are not as resistant and offer a high risk of perforation for the procedure. The success rate of one study revealed $66 \%$ of the complete rupture of the ring. However, in the other $34 \%$, clinical improvement was successful, even without rupture of the device ${ }^{10}$.

The use of a gastric prosthesis, whether plastic or metallic, may be indicated in cases of partial erosion of the band $(<50 \%)$ or when there is an indication for ring extraction, but there is no migration of it to the interior of the gastric chamber8. This procedure causes progressive erosion of the ring into the lumen of the stomach, due to the ischemia caused between the prosthesis and the ring due to the compression of the stomach wall ${ }^{10}$. In the market there is no longer the manufacture of plastic stents previously used (Polyflex - Boston Scientific(B), therefore, currently, metallic stents fully covered for this type of treatment are used.

Prosthesis implantation and extraction procedures are preferably performed in the operating room, under general anesthesia and with the aid of fluoroscopy. External markings with radiopaque materials can be used to facilitate the probable location of the prosthesis, which should encompass the ring in its middle portion. ${ }^{11}$ The proximal end should be located below the level of the diaphragmatic hiatus to avoid pathological gastroesophageal reflux and the distal end should be placed in the efferent loop. After a period of 10 to 15 days, the stents are extracted through the mouth with the aid of grasping forceps, and in that period more than $50 \%$ of the rings are migrated into the gastric chamber. ${ }^{12}$ If the ring is not extracted next to the prosthesis, it can be removed with grasping forceps similar to the removal of a foreign body ${ }^{13}$. However, if it is not extruded, but only apparent in the gastric chamber, it must also be removed after 30 days, with the aid of endoscopic scissors and grasping forceps.

In general, complications related to the procedure are mild, such as nausea/vomiting, abdominal pain, migration, and late stenosis in the ring region, which can be treated with balloon dilation later ${ }^{13}$. Serious complications have not yet been reported in the literature.

Despite being used to increase the restrictive effect of bariatric surgeries, the gastric containment ring is 
prone to complications, such as slipping and erosion and consequent side effects, such as food intolerance. One of the modalities used in the endoscopic treatment of this condition is the endoscopic extraction through the use of Stents and that configures a minimally invasive, safe and effective alternative to the detriment of the surgical treatment that is less and less used due to its higher morbidity and mortality.

\subsection{Justification}

Regarding the use of the gastric retaining ring, although less frequent, it is not uncommon to diagnose some complications related to its use, especially with regard to food intolerance and erosion.

The treatment with balloon dilators, despite having some indications similar to those of stents, provide their rupture without extraction of the ring, which can cause other complications. In addition, there is a correlation with weight regain due to the increase in gastrojejunal anatomy when it involves the dilation procedure. The treatment with stents, although more recent, is effective, safe and has significant success rates. Currently, we only have metallic stents on the market, however for many years plastic stents have been used to extract the gastric containment ring, and there is no meta-analysis study in this segment.

Considering that the endoscopic treatment of complications of the gastric containment ring with the use of stents is already a well-established therapeutic modality in the literature and is a less invasive alternative with a satisfactory success rate, this study aims to characterize the performance of both in a comparative way stents, in the last decade, in relation to clinical resolvability, treatment time and complications in patients previously submitted to Roux-en-Y gastric bypass.

\subsection{Hypothesis}

* Endoscopic interventions with stents to manage complications of the gastric retaining ring are likely to have relevant success rates in the literature; ${ }^{*}$ This therapeutic modality can provide clinical improvement of patients in a less invasive way; ${ }^{*}$ There may be some superiority in performance between the different types of stents used;

\section{OBJECTIVE}

\subsection{Primary}

To analyze the complications of the retaining ring after gastric bypass and the success rates of its resolution via endoscopy with the use of metallic and plastic stents, through systematic review followed by metaanalysis.

\subsection{Secondary}

- Analyze the average erosion time of the retaining ring, both by the metallic and plastic prosthesis;

- Describe whether there was a resolution of food intolerance by the two types of stents;

- Discriminate the resolution of the methods in relation to the respective complications;

- Identify whether there was superior treatment for one of the two stents in relation to the time and resolution of complications.

\section{METHODS}

\subsection{Study design}

This study will follow the international model of Systematic Review and Meta-analysis, following the rules of PRISMA (preferred reporting items for systematic reviews and meta-analysis).

Table 1 shows the main variables of the present study that will be addressed according to the classification of the acronym PICO ( $\mathrm{P}=$ Patients; $\mathrm{I}=$ Intervention; $\mathrm{C}=$ Control; $\mathrm{O}=$ Outcomes $)$.

Table 1. PICO chart (Patients; Intervention; Control; Outcomes). 


\section{PATIENTS}

Intervention

CoNTROL

Outcomes
Bariatric patients (gastric bypass) with complications due to the restrictive ring. Use of metallic and plastic stents to cause erosion of the restrictive ring.

Plastic vs metallic stents.

Resolution of symptoms and complications.

Possible time advantage in the erosion of the ring when comparing stents. Patient satisfaction.

Quality of life analysis.

\subsection{Study eligibility criteria}

The inclusion criteria will be articles that present adult patients and both sexes previously submitted to Roux-en-Y gastric bypass surgery with a containment ring, patients with food intolerance. Articles that present the duration in days of the effective action of plastic or metallic stents to induce ring erosion will also be analyzed, as well as articles that show whether the symptoms have resolved, the success rate of ring removal, the need for endoscopic dilation, adverse events, long-term follow-up for the possibility of weight gain or stenosis formation. Exclusion criteria will be articles that present another procedure for erosion or removal of the ring other than through stents and endoscopic procedures, respectively.

\subsection{Selection of studies and risk of bias in each study}

The study selection will be evaluated by two independent reviewers. Reviewer 1 will perform data extraction and Reviewer 2 will analyze that data. A third investigator will make the final decision to choose the articles and decide on conflicting points. The Cochrane instrument will be adopted to assess the quality of the included studies (Higgins 2011).

\subsection{Data sources and research strategy}

The search strategies for this systematic review will be based on the keywords (MeSH Terms) "Obesity. Endoscopy. Bariatric surgery. Gastric Bypass. Stent", with publications from 2010 to 2020, in order to analyze the most recent scientific publications. The research will be carried out in June 2020 and developed at SCOPUS (Elsevier and non-Elsevier database), PUBMED (MEDLINE biomedical literature, life science magazines, and online books) and SCIENCE DIRECT (Elsevier database), including the National Institutes of Health RePORTER Grant database and clinical trial records. In addition, a combination of the keywords with the Booleans "OR", AND and the operator "NOT" will be used to target scientific articles of interest. The title and abstracts will be examined under all conditions. The research structure used in the databases is shown in Figure 1.

Figure 1. Example of the research structure in PubMed, the same search strategy was used in the other databases.

PubMed Obesity OR gastric bypass Y in Roux OR Restrictive ring OR Food intolerance OR Weight recovery OR Stenos

AND

PubMed Ring erosion OR Stents OR Erosion time OR endoscopic dilation

NOT

PubMed Another procedure for OR ring erosion Another procedure for ring removal

\section{META-ANALYSIS}

The statistical analysis of the data will be performed by an external collaborating professional and interpreted by the main researcher. For data analysis, a database will be built on a Microsoft Excel spreadsheet that will be exported to the Minitab 18ß statistical program (version 18, Minitab, LLC, State College, 
Pennsylvania, USA) (Minitabß) and also to OriginProß 9 (DPR Group, Inc., Northampton, Massachusetts, USA) (Moberly, Bernards, Waynant, 2018). Common descriptive statistical analysis will be performed, obtaining the values of total $\mathrm{N}$, mean, standard deviation, confidence interval (CI), and percentage (frequency) for all predictors. The One-Way test (ANOVA) will be applied, adopting the $\alpha$ level less than 0.05 with a statistically significant difference for the $95 \%$ CI. The value of R-sq (I2) will be analyzed to discover the inaccuracy or heterogeneity of the analyzes. The $\mathrm{S}$ factor will indicate the standard deviation between the data points and the adjusted values.

\section{SCHEDULE}

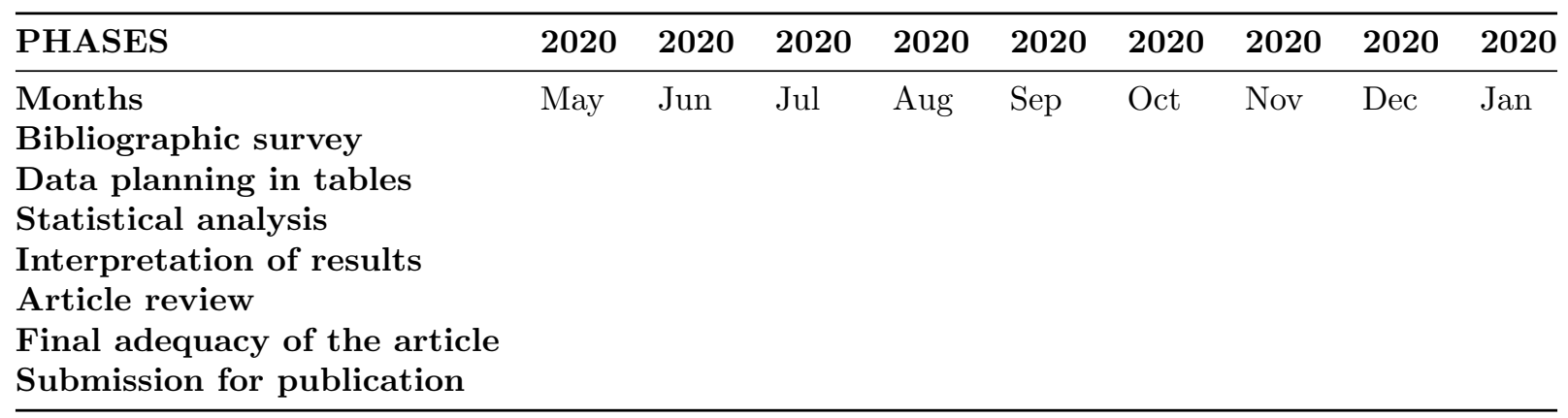

\section{SOURCES OF PROMOTION}

This study will have its own financing and will not have sponsorships or partnerships.

\section{REFERENCES}

1. Ministério da Saúde [homepage na internet]. Em dez anos, obesidade cresce $60 \%$ no Brasil e colabora para maior prevalência de hipertensão e diabetes [acesso em 03/06/2019]. Disponível em: http://www.saude.gov.br/noticias/agencia-saude/28108-em-dez-anosobesidade-cresce-60no-brasil-e-colabora-para-maior-prevalencia-dehipertensao-e-diabetes

2. Kumar N. Endoscopic therapy for weight loss: Gastroplasty, duodenal sleeves, intragastric balloons, and aspiration. World J Gastrointest Endosc. 2015 Jul;7(9):847-859.

3. Bispo M, Silva MJF, Bana T, Seves I, Couto G, Peixe P, et al . O Balão Intra-Gástrico no Tratamento da Obesidade: Avaliação da Sua Eficácia, Segurança e Tolerabilidade. J Port Gastrenterol. 2008 Jun;15(3):103-109.

4. Sociedade Brasileira de Cirurgia Bariatrica e metabólica [homepage na internet]. Número de cirurgias bariátricas no Brasil aumenta 46,7\%; 11 de julho de 2018 [acesso em 03/06/2019]. Disponível em: https://www.sbcbm.org.br/numero-de-cirurgias-bariatricas-no-brasil-aumenta-467/

5. Tavares A, Viveiros F, Cidade C, Maciel J, Cirurgia Bariátrica Do Passado ao Século XXI. Serviço de Cirurgia Geral do Centro Hospitalar de Vila Nova de Gaia/Espinho. Vila Nova de Gaia. Acta Med Port 2011;24:111-16 .

6. Blero D, Eisendrath P, Vandermeeren A, Closset, J, Mehdi A, Le Moine O, et al. Endoscopic removal of dysfunctioning bands or rings after restrictive bariatric procedures. Brussels, Belgium. Gastrointestinal Endoscopy, Volume 71, No. $3: 2010$.

7. Huang CS, Farraye FA. Endoscopy in the Bariatric Surgical Patient. Gastroenterol Clin North Am. 2005 Mar;34(1):151-66.

8. Joo MK. Endoscopic Approach for Major Complications of Bariatric Surgery. Clin Endosc 2017;50(1):31-41.

9. Campos JM, Moon RC, Magalhães Neto GEJ. Endoscopic treatment of food intolerance after a banded gastric bypass: inducing band erosion for removal using a plastic Prótese; Marins Campos Josemberg et al. Universidade Federal de Pernambuco. 2016.

10. Campos JM, Evangelista LF, Ferraz AAB, Galvao Neto MP, De Moura EGH, Sakai P. Treatment of 
ring slippage after gastric bypass: long-term results after endoscopic dilation with an achalasia balloon (with videos). Gastrointestestinal Endosc. 2010 Jul;72(1):44-9.

11. Rai RR, Shende A, Joshi A, et al. Rigiflex pneumatic dilation of achalasia without fluoroscopy: a novel office procedure. Gastrointest Endosc 2005 Set;62:427-31.

12. Ferraz A, Campos J, Dib V et al. Food intolerance after banded gastric bypass without stenosis: aggressive endoscopic dilation avoids reoperation. Obes Surg 2013; 23: 959-964.

13. Marins Campos J, Moon RC, Magalhães Neto GE, Teixeira AF, Jawad MA, Bezerra Silva L. Endoscopic treatment of food intolerance after a banded gastric bypass: inducing band erosion for removal using a plastic Prótese. Endoscopy. 2016 Jun;48(6):516-20.

14. Wilson T, Miller N, Brown N et al. Stent induced gastric wall erosion and endoscopic retrieval of nondjustable gastric band: a new technique. Surg Endosc 2013 May; 27:17-1621.

15. Higgins J, Green S. Cochrane Handbook for Systematic Reviews of Interventions. Version 5.1.0 [updated March 2011]. The Cochrane Collaboration; 2011.

16. Minitab@, Quality. Analysis. Results and the Minitab logo are registered trademarks of Minitab, Inc., in the United States and other countries. Additional trademarks of Minitab Inc. can be found at www.minitab.com. All other marks referenced remain the property of their respective owners.

17. Moberly JG, Bernards MT, Waynant KV. Key features and updates for origin 2018. J Cheminform. 2018 Feb 9;10(1):5 [doi: 10.1186/s13321-018-0259-x]. 